\title{
PROPRIEDADES FÍSICAS DO SOLO EM ÁREA SOB MILHO EM MONOCULTIVO OU CONSORCIADO COM LEGUMINOSAS DE VERÃO(1)
}

\author{
Emerson Dalla Chieza ${ }^{(2)}$, Thomé Lovato ${ }^{(3)}$, Ednaldo Da Silva Araújo ${ }^{(4)}$ \& Jonatan Tonin $^{(5)}$
}

\begin{abstract}
RESUMO
O uso de plantas de cobertura é uma prática que pode prover melhorias na qualidade física dos solos. Objetivou-se com este trabalho avaliar o potencial de consórcios entre leguminosas de verão e milho, na melhoria de propriedades físicas do solo. $O$ estudo foi conduzido em campo no período entre setembro de 2008 e setembro de 2009, em um Argissolo no município de Santa Maria, RS. O delineamento experimental foi em blocos ao acaso, com cinco tratamentos e quatro repetições. Os tratamentos consistiram nos seguintes cultivos: milho + feijão-caupi, milho + guandu anão, milho + mucuna-preta, milho em monocultivo, além de uma área em pousio como testemunha. Em cada parcela, foram coletadas amostras indeformadas do solo nas profundidades de 0-5 e 5-10 cm em três épocas: na instalação do experimento, aos 30 dias após a deposição da palhada de cada cultivo sobre o solo e um ano após a instalação do experimento. Foram mensurados os seguintes atributos: densidade do solo, porosidade total, macro e microporosidade e estabilidade dos agregados. Todos os cultivos estudados diminuíram a densidade do solo e aumentaram a macroporosidade e a porosidade total na profundidade de 0-5 cm do solo, em comparação à área em pousio. $O$ consórcio de milho e guandu anão aumentou o diâmetro médio ponderado de agregados na profundidade de 0-5 cm do solo, em relação ao tratamento em pousio, mas esse efeito foi temporário, pois não persistiu até a coleta final. $O$ consórcio entre milho e guandu anão foi o mais promissor em promover melhorias na estrutura do solo.
\end{abstract}

Termos de indexação: densidade do solo, estrutura do solo, estabilidade de agregados, adubação verde.

\footnotetext{
(1) Parte da Dissertação de Mestrado do primeiro autor, apresentada ao Programa de Pós-Graduação em Ciência do Solo - Universidade Federal de Santa Maria - UFSM. Recebido para publicação em 15 de dezembro de 2011 e aprovado em 6 de junho de 2013.

(2) Doutorando no Programa de Pós-Graduação em Fitotecnia, Universidade Federal Rural do Rio de Janeiro - UFRRJ. BR 465, Km 47, Zona Rural. CEP 23890-000 Seropédica (RJ). E-mail: echieza@gmail.com

(3) Professor Adjunto, Departamento de Solos, Centro de Ciências Rurais, UFSM. Av. Roraima, 1000, Camobi. CEP 97105-900 Santa Maria (RS). E-mail: thome.ufsm@gmail.com

(4) Pesquisador, Embrapa Agrobiologia. Antiga rodovia Rio-São Paulo, Km 47. CEP 23890-000 Seropédica (RJ). E-mail: ednaldo. araujo@embrapa.br

(5) Acadêmico do curso de Agronomia, UFSM. E-mail: jonatonin@yahoo.com.br
} 


\title{
SUMMARY: SOIL PHYSICAL PROPERTIES UNDER MAIZE IN MONOCULTURE OR INTERCROPPED WITH SUMMER LEGUMES
}

\begin{abstract}
The use of cover crops is a practice that can improve the physical quality of soils. The objective of this work was to evaluate the potential of intercropping of summer legumes with maize to improve soil physical properties. The study was conducted in the field from September 2008 to September 2009, in an Ultisol in Santa Maria, Rio Grande do Sul. The experiment was arranged in a randomized block design with five treatments and four replications. The treatments consisted of the consortia: maize + cowpea, maize + dwarf pigeonpea, maize + velvet bean, monoculture maize, and a fallow area as control. Samples were collected from the soil layers $0-5$ and $5-10 \mathrm{~cm}$ three times per plot (at the beginning of the experiment, 30 days after leaving the residues of each crop on the soil surface, and one year after the beginning of the experiment). We measured the following properties: soil bulk density, porosity, macro- and microporosity, and aggregate stability. All crops decreased bulk density and increased macroporosity and total porosity in the $0-5 \mathrm{~cm}$ soil, compared to the fallow area. The consortium of maize and pigeonpea increased the mean weighted diameter of aggregates in the $0-5 \mathrm{~cm}$ layer, compared to the fallow treatment, but this effect was temporary, and had disappeared by the last measurement. The intercropping of maize and dwarf pigeonpea was the most promising for improvements in the soil structure.
\end{abstract}

Index terms: bulk density, soil structure, aggregate stability, green manure.

\section{INTRODUÇÃO}

O uso de plantas de cobertura de solo, em especial as de verão, é uma prática conservacionista que pode prover melhorias na qualidade física dos solos, por meio de seu potencial efeito sobre a densidade volumétrica, porosidade, condutividade hidráulica, agregação etc, sendo que essas exercem influência direta sobre a estrutura desses (Argenton et al., 2005).

A formação dos agregados do solo, segundo o conceito hierárquico proposto por Tisdall \& Oades (1982), parte da formação de microagregados $(<250$ $\mu \mathrm{m})$ pela união entre partículas primárias livres ligadas por agentes persistentes, como matéria orgânica humificada, cátions polivalentes, entre outros. A partir da união entre esses microagregados estáveis, por agentes temporários (hifas de fungos e raízes) ou transientes (polissacarídeos provenientes de microrganismos ou plantas) formam-se os macroagregados. Isto demonstra a importância da matéria orgânica na formação e na estabilidade dos agregados do solo, o que é bastante relatado na literatura (Abiven et al., 2009). A matéria orgânica pode contribuir diretamente para agregação do solo pela ação cimentante e indiretamente, como fonte de alimento para os microrganismos (Six et al., 2004).

A agregação está diretamente relacionada com a porosidade do solo, que representa o espaço em que ocorrem os processos dinâmicos dos gases e da solução do solo (Eden et al., 2011). Essas áreas estão diretamente relacionadas com a densidade volumétrica do solo, pois quanto maior o espaço ocupado pelas partículas, menor será o volume do espaço poroso. Os macroporos estão relacionados com as trocas gasosas e com os processos de drenagem, as quais interferem no desenvolvimento das culturas e na qualidade ambiental (Abreu et al., 2004); já os microporos, com os processos de retenção de água no solo (Michelon et al., 2010).

Silva et al. (2006) comentam a importância da formação e estabilidade dos agregados. Ao fazer uma ponderação entre a agregação do solo e produtividade dos sistemas de cultivo, esses autores destacam que a agregação do solo diminui notadamente com o preparo do solo, principalmente em solos mais frágeis como os de textura arenosa.

Segundo Wohlenberg et al. (2004), solos fisicamente degradados podem ser recuperados com sistemas de manejo de solo e de culturas, por meio do cultivo de espécies com diferentes sistemas aéreos e radiculares que adicionam elevada quantidade de material orgânico. Nesse sentido, espécies utilizadas na adubação verde podem contribuir na composição de consórcios que favoreçam melhorias nas propriedades físicas do solo. Diversos estudos têm demonstrado o potencial da adubação verde em sistemas de consórcio em prover melhorias em diversos atributos do solo (Lovato et al., 2004; Silva et al., 2011). Entretanto, ainda há carência de estudos que demonstrem os efeitos do consórcio de milho com leguminosas, sobretudo as espécies com crescimento estival sobre os atributos físicos do solo.

Diante do exposto, objetivou-se com este trabalho avaliar o efeito do cultivo de milho, em monocultivo ou consorciado com leguminosas de verão, sobre a estabilidade de agregados, densidade do solo, porosidade total, macro e microporosidade do solo.

\section{MATERIAL E MÉTODOS}

Este trabalho foi realizado entre setembro de 2008 e setembro de 2009, no Assentamento de Reforma 
Agrária Carlos Marighella, no município de Santa Maria, RS (29 $\left.39^{\prime} \mathrm{S} ; 53^{\circ} 53^{\prime} \mathrm{W}\right)$, com altitude média de $110 \mathrm{~m}$. O clima da região é classificado como Cfa (subtropical úmido), conforme classificação de Köppen. O comportamento das precipitações pluviais e temperaturas médias locais e as ocorridas durante o período do experimento estão apresentados na figura 1.

O solo da área é classificado como Argissolo Vermelho distrófico arênico, pertencente à Unidade de Mapeamento São Pedro (Streck et al., 2008). No início do experimento, foram coletadas amostras de solo nas profundidades de $0-5$ e $5-10 \mathrm{~cm}$ a fim de caracterizá-lo fisicamente, segundo métodos descritos por Claessen (1997), e quimicamente, de acordo com Tedesco et al. (1995). Para a análise granulométrica, utilizou-se o método da pipeta e para determinações da densidade do solo e da porosidade, o do anel volumétrico. No quadro 1, são apresentados os resultados para os atributos químicos e físicos do solo.

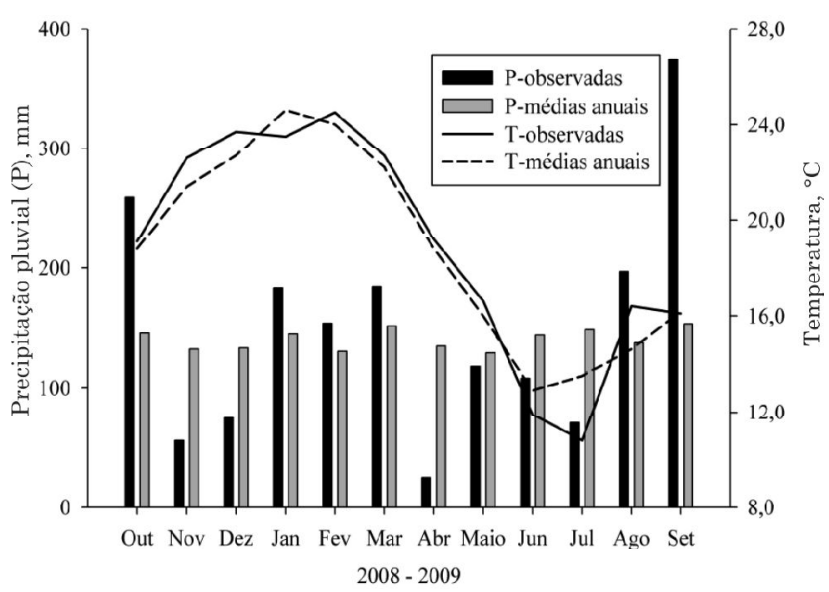

Figura 1. Precipitações pluviais (coleta in loco) e temperaturas médias (INMET) observadas e normais para o período de outubro de 2008 a setembro de 2009, em Santa Maria, RS.

Quadro 1. Atributos químicos e físicos de um Argissolo Vermelho distrófico arênico nas profundidades avaliadas

\begin{tabular}{lcc}
\hline \multirow{2}{*}{ Atributo } & \multicolumn{2}{c}{ Profundidade $(\mathbf{c m})$} \\
\cline { 2 - 3 } & $\mathbf{0 - 5}$ & $\mathbf{5 - 1 0}$ \\
\hline $\mathrm{pH}\left(\mathrm{H}_{2} \mathrm{O}\right)(1: 1)$ & 5,3 & 5,2 \\
$\mathrm{Ca}^{+2}, \mathrm{cmol}_{\mathrm{c}} \mathrm{dm}^{-3}$ & 2,5 & 2,5 \\
$\mathrm{Mg}^{+2}, \mathrm{cmol}_{\mathrm{c}} \mathrm{dm}^{-3}$ & 1,2 & 1,0 \\
$\mathrm{P}, \mathrm{mg} \mathrm{dm}^{-3}$ & 12,1 & 8,6 \\
$\mathrm{~K}, \mathrm{mg} \mathrm{dm}^{-3}$ & 47,7 & 22,7 \\
Matéria orgânica, $\mathrm{g} \mathrm{kg}^{-1}$ & 13,0 & 12,0 \\
Areia, g kg & 590 & 620 \\
Silte, g kg & 250 & 210 \\
Argila, g kg & 160 & 170 \\
\hline
\end{tabular}

A área estava sob pousio durante três anos, onde se estabeleceu vegetação espontânea, prevalecendo espécies de gramíneas, sobretudo as do gênero Andropogon. Em setembro de 2008, a área foi submetida à dessecação com Glifosato + 2,4 D-amina $\left(1736+1440 \mathrm{~g} \mathrm{ha}^{-1}\right.$ do IA, respectivamente), para que em outubro recebesse a semeadura do milho (Zea mays) e das plantas de cobertura de verão. Um dia antes da semeadura, com base na análise do solo, foi realizada a aplicação de calcário dolomítico $\left(200 \mathrm{~kg} \mathrm{ha}^{-1}\right.$, PRNT $76 \%$ ) e a adubação $\left(80,75,75 \mathrm{~kg} \mathrm{ha}^{-1}\right.$, para N, P e K, respectivamente), sendo ambas as aplicações realizadas em superfície. Foram utilizados esses valores a partir das recomendações de CQFS/RS-SC (2004), para atingir pH de 5,5 e patamar de produção de $4 \mathrm{Mg} \mathrm{ha}^{-1}$, para a cultura do milho. $\mathrm{O} \mathrm{N}$ foi aplicado, nas linhas de plantio, de forma parcelada, sendo $25 \%$ na semeadura e o restante 35 dias após a semeadura. Todos os manejos realizados durante o experimento não resultaram em revolvimento significativo do solo.

A semeadura do milho foi efetuada com auxílio de uma máquina de plantio direto com tração animal, regulada para uma densidade de cinco sementes por metro linear, distanciado $0,8 \mathrm{~m}$ entrelinhas $(62.000$ plantas ha-1). As plantas de cobertura de solo de verão, entretanto, foram semeadas em covas, nas entrelinhas da cultura do milho, sendo utilizadas as espécies: feijão caupi (Vigna unguiculata), 80.000 covas ha $^{-1}$; guandu anão (Cajanus cajan), 65.000 covas ha $^{-1}$; e mucuna preta (Mucuna aterrima), 35.000 covas ha-1.

O experimento foi composto por cinco tratamentos, organizados em delineamento experimental de blocos casualizados, com quatro repetições em parcelas $4 \mathrm{x}$ $15 \mathrm{~m}$. Os tratamentos consistiram nos seguintes cultivos: milho + feijão caupi $(\mathrm{M}+\mathrm{FC})$; milho + guandu anão (M + GA); milho + mucuna preta $(\mathrm{M}+\mathrm{MP})$; milho em monocultivo (Mon); e área mantida sob pousio (PO).

A cultura do milho foi colhida em março de 2009. Em virtude da necessidade de efetuar a colheita de sementes das plantas de cobertura de solo, o que é uma atividade importante e relativamente comum em pequenas propriedades, o manejo dessas (corte e deposição da fitomassa sobre o solo) ocorreu em diferentes datas, sendo o feijão caupi manejado em março; o guandu anão, em maio e a mucuna preta, em junho de 2009.

As amostragens de solo foram obtidas em três diferentes fases da avaliação: em outubro de 2008, imediatamente antes da semeadura, fase inicial; em setembro de 2009, fase final; e por ocasião do manejo das plantas de cobertura do solo, fase manejos. Foram efetuadas coletas para determinações de densidade do solo, macroporosidade, microporosidade e porosidade total, além da estabilidade de agregados para todos os tratamentos nas fases "inicial" e "final". Por ocasião da colheita das plantas de coberturas (fase manejos), coletaram-se amostras do solo somente para determinações da estabilidade dos agregados, aproximadamente 30 dias após o manejo de cada 
cultivo. Assim, em cada data de manejo, foram retiradas amostras de solo do cultivo que havia sido manejado há 30 dias, bem como do tratamento que estava em pousio, que foi utilizado como referência, pois não sofreu intervenções.

Para cada coleta efetuada, foram abertas, com auxilio de pá de corte, seis trincheiras com $30 \mathrm{~cm}$ de profundidade em cada parcela. Em cada trincheira, preservaram-se dois lados, que não receberam compressão. Em um dos lados de cada trincheira, em todas as coletas, retiraram-se amostras indeformadas em monólitos ( $5 \times 10 \times 20 \mathrm{~cm}$ ), que foram utilizadas para determinar a estabilidade dos agregados. Já o outro lado, somente em outubro de 2008 e setembro de 2009, fases de avaliação inicial e final, respectivamente, foi utilizado para coleta de amostras para definir a densidade do solo, macroporosidade, microporosidade e porosidade total do solo.

Os monólitos de solo coletados foram fracionados manualmente, observando-se os pontos de fraqueza, sem uso de compressão, até o volume total coletado transpassar na malha de $8,00 \mathrm{~mm}$ e ficar retido na peneira de $2,00 \mathrm{~mm}$. Essa massa de agregados foi seca ao ar por 15 dias e acondicionada em potes plásticos por no máximo três meses até sua análise.

Para análise dos agregados, utilizou-se o método descrito por Kemper \& Chepil (1965), com alteração no tamanho de agregados, em que se utilizaram agregados entre 8,00 e 2,00 mm. Optou-se pelo método modificado para evitar superestimar os parâmetros relacionados à agregação do solo, uma vez que existe tendência de expressar valores maiores quando se utiliza o método-padrão, o que pode ser observado no trabalho de Reichert et al. (2006).

Cada amostra foi analisada em duplicata. A separação em classes foi obtida por peneiramento úmido. Para cada análise, foram colocados aproximadamente $25 \mathrm{~g}$ da massa de agregados secos ao ar sobre um jogo de peneiras sobrepostas $(4,76$; 2,$00 ; 1,00$; e $0,21 \mathrm{~mm}$ ), sendo essa massa previamente reumedecida por $10 \mathrm{~min}$, com posterior imersão em água e agitação num oscilador vertical (30 oscilações por $\mathrm{min}$ ) por mais $10 \mathrm{~min}$. Após esse processo, retirouse a massa retida em cada peneira, colocada em recipiente apropriado e levada à estufa $105{ }^{\circ} \mathrm{C}$ por 48 h. Posteriormente, cada amostra foi pesada e submetida à desagregação para averiguação de partículas unitárias, que podiam ocasionar a superestimação de valores. Para as amostras em que se utilizaram as peneiras maiores que $2,00 \mathrm{~mm}$, esse procedimento foi mecânico com auxílio de um bastão de vidro; para peneiras menores que $2,00 \mathrm{~mm}$, as amostras foram inundadas com $\mathrm{NaOH}\left(1 \mathrm{~mol} \mathrm{~L}^{-1}\right)$, que é um agente dispersante, por $5 \mathrm{~min}$.

Depois de desagregadas, levaram-se as amostras novamente às suas respectivas peneiras, onde foram lavadas com jatos de água. As partículas unitárias, representadas normalmente por grãos de areia e cascalho, retidos nas peneiras, foram levadas novamente à estufa a $105^{\circ} \mathrm{C}$ por $24 \mathrm{~h}$. Transcorrida essa etapa, o material coletado foi pesado e o valor obtido foi descontado da massa de agregados retida na respectiva peneira, durante o processo de peneiramento úmido.

A distribuição dos agregados em classes e a determinação do diâmetro médio ponderado (DMP) foram feitas, aplicando-se as seguintes fórmulas:

$$
\% \text { de agregados na classe }{ }_{i}=\left(\mathrm{MA}_{\mathrm{i}} / \mathrm{MAT}\right) * 100
$$

$$
\mathrm{DMP}=\Sigma\left(\mathrm{MA}_{\mathrm{i}} * \Phi_{\mathrm{i}}\right) / \mathrm{MAT},
$$

em que: $\mathrm{MA}_{\mathrm{i}}$ é a massa de agregados retidos na peneira que representa a classe de agregados, descontadas as partículas unitárias; MAT, o somatório total da massa de agregados, descontadas as partículas unitárias; e $\Phi_{i}$, média dos diâmetros entre a peneira onde ficou retida a massa de agregados e a peneira de diâmetro imediatamente superior a essa.

Para as determinações densidade do solo, porosidade total, macroporosidade e microporosidade, foram retiradas amostras por meio da introdução de anéis metálicos no solo, nas camadas de 0-5 e 5-10 cm de profundidade, os quais dispunham um volume interno conhecido. Em seguida, os anéis foram retirados com as amostras e solo em excesso. No laboratório, foi realizada a retirada do excesso de solo no anel, de modo que a quantidade de solo (amostra) ficasse compreendida entre os limites dele.

Posteriormente, os anéis com as amostras foram depositados por $48 \mathrm{~h}$ em um recipiente com lâmina de água de aproximadamente $2,0 \mathrm{~cm}$ de altura, para que as amostras fossem saturadas. Em seguida, essas foram pesadas e acondicionadas em mesa de tensão, onde foram submetidas a uma tensão máxima de $0,6 \mathrm{~m}$ de coluna de água, para drenar a água retida nos macroporos (poros $>50 \mu \mathrm{m}$ ), sendo mantidas nessa condição até atingirem peso constante. Quando os valores da massa estabilizaram, os anéis foram novamente pesados para que depois fossem levados à estufa $105^{\circ} \mathrm{C}$, por $48 \mathrm{~h}$. Transcorrida essa etapa, as amostras foram novamente pesadas e, descontandose a massa do anel em cada etapa da obtenção da massa, aplicaram-se as seguintes fórmulas aos dados:

Macroporosidade $(\%)=[(\mathrm{SS}-\mathrm{SU}) / \mathrm{Vol}.]{ }^{*} 100$

Microporosidade $(\%)=[(\mathrm{SU}-\mathrm{SE}) / \mathrm{Vol} .]^{*} 100$

Porosidade total $(\%)=$ macroporosidade $(\%)+$ microporosidade (\%)

Densidade do solo $\left(\mathrm{kg} \mathrm{dm}^{-3}\right)=\mathrm{SE} / \mathrm{Vol}$.

em que SS é a massa do solo saturado; SU, a massa do solo que recebeu a tensão de $0,6 \mathrm{~m}$ de coluna de água; SE, a massa de solo seco em estufa a $105^{\circ} \mathrm{C}$; e Vol., o volume interno do anel.

Submeteram-se os dados à análise de variância e, quando significativos, as médias foram avaliadas pelo teste de Tukey a $5 \%$. Para tais análises, utilizou-se o pacote estatístico SISVAR ${ }^{\circledR} 5.3$ (Ferreira, 2011). 


\section{RESULTADOS E DISCUSSÃO}

O cultivo do milho consorciado ou não com leguminosas resultou na redução significativa $(\mathrm{p}<0,05)$ da densidade do solo (Ds), quando comparado ao tratamento em pousio ou à condição do solo no início do estudo (Quadro 2). Na amostragem inicial do experimento, a Ds encontrava-se, nas duas profundidades de amostragem, acima de $1,4 \mathrm{Mg} \mathrm{ha}^{-1}$ encontrado por Silva et al. (2000), em um solo de textura franca, semelhante ao deste estudo. Embora esses autores não tenham encontrado diferenças na produtividade de milho, eles alertam que em períodos de estresse hídrico essa condição de Ds pode se tornar fator limitante à produtividade do milho.

No entanto, os valores de Ds estão abaixo de $1,75 \mathrm{~g} \mathrm{~cm}^{-3}$, que foi o limite crítico estabelecido por Reinert et al. (2008), para plantas de cobertura com crescimento em período estival, como as utilizadas neste experimento, em um solo de textura semelhante ao deste estudo. Os autores enfatizam que densidades acima desse limite podem ocasionar impedimentos físicos ao crescimento das raízes, com danos significativos para as culturas. Portanto, os dados observados neste trabalho indicam condições potencialmente danosas à produtividade da cultura do milho, porém com avanços significativos nos tratamentos que receberam as plantas de cobertura do solo (Quadro 2). Esses dados corroboram com aqueles obtidos por Lanzanova et al. (2010), evidenciando o papel das plantas de cobertura na melhoria das propriedades físicas do solo.

Observou-se que na área em pousio também ocorreu redução da Ds em relação à coleta inicial, realizada na semeadura; como não houve qualquer intervenção nessa área, credita-se à vegetação espontânea relevante contribuição para esse resultado. Os sistemas de consórcios não diferiram estatisticamente entre si $(p<0,05)$, porém todos esses diferiram em relação à área em pousio, o que demonstra o efeito benéfico dos cultivos sobre esse atributo.

Reinert et al. (2008) comentam que plantas de cobertura de solo de verão, como as usadas neste estudo, têm potencial para mitigar os efeitos da compactação pelos bioporos formados por suas raízes, que geralmente são agressivas, bem como diminuir a Ds, principalmente nas camadas superficiais. Andrade et al. (2009), analisando um experimento com sistemas de cultivos que dispunham de guandu, encontraram ganhos na camada superficial para os cultivos anuais que, inclusive, superaram os dados da mata, usada como área referência por esses autores.

Nas áreas cultivadas, na profundidade de $0-5 \mathrm{~cm}$, observaram-se aumentos significativos $(p<0,05)$ para os macroporos em relação à área em pousio, bem como em relação à condição inicial (Quadro 2). Os macroporos, dentre outras funções, são os principais responsáveis pelas trocas gasosas do solo. Segundo Silva et al. (2004), para garantir adequado fluxo de trocas gasosas, são necessários no mínimo $10 \%$ de macroporos. Dessa maneira, todos os tratamentos apresentaram uma porcentagem de macroporos adequada. Característica importante também é a quantidade de macroporos em relação à porosidade total, pois indica a relação entre capacidade de aeração e capacidade de retenção de água no solo; seu valor ideal, segundo Genro Junior et al. (2009), é de 0,33. Para o estudo em questão, os valores situaram-se em uma faixa entre 0,29 e 0,40. Portanto, estão próximos à relação considerada ideal, sendo os maiores valores observados na camada de $0-5 \mathrm{~cm}$ para todos os sistemas de cultivo estudados.

Quadro 2. Efeito dos sistemas de cultivos de milho em monocultivo (Mon) ou consorciados com feijão-caupi (M + FC), guandu anão (M + GA) e mucuna-preta (M + MP) na densidade volumétrica (Ds), macroporos, microporos e porosidade total do solo, em duas profundidades de amostragem

\begin{tabular}{|c|c|c|c|c|c|c|c|}
\hline \multirow{2}{*}{ Atributo } & \multirow{2}{*}{ Amostragem inicial } & \multicolumn{4}{|c|}{ Sistema de cultivo } & \multirow{2}{*}{ Pousio } & \multirow{2}{*}{$\mathrm{CV}$} \\
\hline & & $\mathbf{M}+\mathbf{F C}$ & $\mathbf{M}+\mathbf{G A}$ & $\mathbf{M}+\mathbf{M P}$ & Mon & & \\
\hline & & & & & & & $\%$ \\
\hline & \multicolumn{7}{|c|}{$0-5 \mathrm{~cm}$} \\
\hline Ds $\left(\mathrm{kg} \mathrm{dm}^{-3}\right)$ & $1,59 \mathrm{a}$ & $1,47 \mathrm{c}$ & $1,44 \mathrm{c}$ & $1,48 \mathrm{c}$ & $1,44 \mathrm{c}$ & $1,52 \mathrm{~b}$ & 6,8 \\
\hline Macroporos (\%) & $11,8 \mathrm{~b}$ & $15,0 \mathrm{a}$ & $16,0 \mathrm{a}$ & $15,7 \mathrm{a}$ & $15,2 \mathrm{a}$ & $10,8 \mathrm{~b}$ & 22,7 \\
\hline Microporos (\%) & 23,9 & 24,0 & 23,9 & 24,9 & 24,9 & 25,2 & 4,8 \\
\hline \multirow[t]{2}{*}{ Porosidade total (\%) } & $35,7 \mathrm{~b}$ & 39,0 a & 39,9 a & 40,6 a & $40,1 \mathrm{a}$ & $36,0 \mathrm{~b}$ & 7,0 \\
\hline & \multicolumn{7}{|c|}{$5-10 \mathrm{~cm}$} \\
\hline Ds $\left(\mathrm{kg} \mathrm{dm}^{-3}\right)$ & 1,63 & 1,57 & 1,57 & 1,60 & 1,57 & 1,60 & 2,8 \\
\hline Macroporos (\%) & 10,5 & 11,0 & 10,7 & 9,5 & 11,8 & 11,6 & 22,0 \\
\hline Microporos (\%) & 23,4 & 21,8 & 22,4 & 22,8 & 22,0 & 20,2 & 6,4 \\
\hline Porosidade total (\%) & 32,9 & 32,8 & 33,1 & 32,3 & 33,8 & 31,8 & 6,9 \\
\hline
\end{tabular}

Letras minúsculas comparam médias na linha pelo teste de Tukey a $5 \%$. Ausências de letras correspondem a diferenças estatísticas não significativas. 
Contudo, na camada de $5-10 \mathrm{~cm}$ de profundidade não ocorreram alterações significativas $(p<0,05)$ para Ds, porosidade total, macro e microporosidade. Naturalmente, à medida que se aumenta a profundidade têm-se menor volume e atividade de raízes, que são fatores diretamente relacionados com esses atributos (Andrade et al., 2009).

Já para os microporos, não foram observadas diferenças significativas $(\mathrm{p}<0,05)$ (Quadro 2). Segundo Silva \& Kay (1997), esse atributo é relativamente menos influenciado pelos manejos do solo do que os macroporos, principalmente por ter correlação com a textura e os teores de carbono do solo. Assim, para observar possíveis variações desse atributo, normalmente são necessários estudos com um período de avaliação superior ao dedicado neste experimento. Variações da microporosidade foram observadas por Pereira et al. (2010), os quais avaliaram plantas de cobertura em pré-cultivo e diferentes sistemas de preparo do solo durante mais de cinco anos. Portanto, o aumento na porosidade total observado neste experimento (Quadro 2) deve-se ao incremento de macroporos.

Observou-se que durante o período de estudo ocorreu redução $(p<0,05)$ no percentual de agregados da classe de 8,00-4,76 $\mathrm{mm}$ em praticamente todos os sistemas de cultivos, bem como na área em pousio; no entanto, apenas o consórcio entre milho e feijão caupi (M + FC) não apresentou esse comportamento (Quadro 3). Essa redução foi mais pronunciada no tratamento pousio, na profundidade de $0-5 \mathrm{~cm}$, que foi superior a $24 \%$. Entretanto, esse fato não influenciou de forma significativa $(p<0,05)$ a estabilidade dos agregados, representado pelo diâmetro médio ponderado (DMP), em ambas as camadas estudadas (Quadro 3). Isso deve-se provavelmente à maioria dos agregados que reduziram o diâmetro ter permanecido na classe imediatamente inferior (4,76-2,00 $\mathrm{mm})$.

Como durante o estudo ocorreram períodos de estiagem (Figura 1), acreditou-se que também possa ter ocorrido a diminuição da atividade das raízes, bem como da atividade biológica, importantes para formação e manutenção dos macroagregados, o que pode ter contribuído para diminuição de agregados da classe de 8,00-4,76 mm na camada superficial do solo. Os ciclos de umedecimento e secagem do solo também podem ter influenciado nesse processo, conforme demonstrado por Bastos et al. (2005), os quais ressaltam os efeitos negativos que esses ciclos têm sobre a estabilidade dos agregados.

Para o tratamento pousio, esperou-se comportamento similar ao obtido por Wohlenberg et al. (2004), os quais demonstraram que áreas sem revolvimento do solo e com vegetação estabelecida tendem a ter menor variação temporal na estabilidade de agregados. Todavia, observou-se redução do estado de agregação nessa área, para as duas profundidades estudadas (Quadro 3). Isto sugere que as condições ambientais não foram favoráveis à manutenção do estado de agregação.

Embora estudos como o de Lovato et al. (2004) relatem estreita correlação entre carbono orgânico do solo e estabilidade de agregados, neste estudo encontrou-se coeficiente de correlação entre esses fatores de 0,22 e -0,05 (dados não apresentados) para as camadas de $0-5$ e $5-10 \mathrm{~cm}$ de profundidade, respectivamente, o que é insuficiente para explicar as variações no DMP sob os diferentes sistemas de cultivo. Segundo Silva \& Mielniczuk (1998), embora exista essa relação estreita entre esses dois fatores, nem sempre essa se expressa de modo preponderante, em razão da ação de outros fatores, como atividade das raízes, por exemplo, que, em determinadas situações, desempenham papel determinante na formação e manutenção dos macroagregados.

O tratamento $\mathrm{M}+\mathrm{GA}$ influenciou positivamente o DMP na profundidade de $0-5 \mathrm{~cm}$ na fase de manejo (Figura 2a,b), que compreende as avaliações feitas 30 dias após a roçada e deposição da palhada sobre o solo, apesar de ser temporário, já que não se observaram diferenças significativas $(\mathrm{p}<0,05)$ em relação à coleta na fase final (Quadro 3). Considerou-se esse efeito bastante relevante, já que ocorreu no inverno, justamente num período em que o solo fica relativamente mais exposto, pois permanece sem uma cobertura viva até a implantação da cultura subsequente. Ademais, o inverno no sul do Brasil é, normalmente, chuvoso, ou seja, esse efeito ocorreu num período em que um dos principais fatores erosivos (impacto da gota da chuva) ocorre com maior frequência. Andrade et al. (2009) também encontraram benefícios à qualidade física do solo proporcionados pelo guandu em sistemas de cultivos avaliados por mais de cinco anos.

Em razão desse efeito temporário, destacou-se a importância de se manterem plantas de cobertura de solo durante todo ano, de preferência as que dispõem de rápido crescimento inicial e alta atividade de raízes, bem como alta capacidade de aporte de material orgânico, como ressaltado por Vezzani \& Mielniczuk (2011). Se por um lado, a atividade das raízes, o aporte de biomassa e a rápida decomposição das plantas favoreceram a agregação do solo (Ambrosano et al., 2009), por outro, a ausência de cultivos subsequentes no inverno, em médio prazo, pode ocasionar efeito negativo na agregação, provocada pela ausência do crescimento de raízes, bem como decréscimo na atividade biológica pela insuficiência de biomassa (Reichert et al., 2003), seja pela escassez de alimento ou mesmo pela menor proteção da biota do solo perante às variações climáticas.

Também na fase de manejo, na profundidade de 5$10 \mathrm{~cm}$, observou-se redução significativa $(p<0,05)$ para o DMP no tratamento M + FC (Figura 2b). Essa redução foi 10,5 e $8 \%$ inferiores ao pousio e à condição inicial, respectivamente. Possivelmente, esse resultado esteja relacionado com a condição de estresse hídrico 
Quadro 3. Distribuição dos agregados em classes de tamanho e diâmetro médio ponderado (DMP) para as camadas de 0-5 e 5-10 cm de profundidade do solo, submetidos ao efeito de pousio e dos sistemas de cultivo: milho + feijão-caupi (M + FC); milho em monocultivo (Mon); milho + guandu anão (M + GA) e milho + mucuna-preta (M + MP)

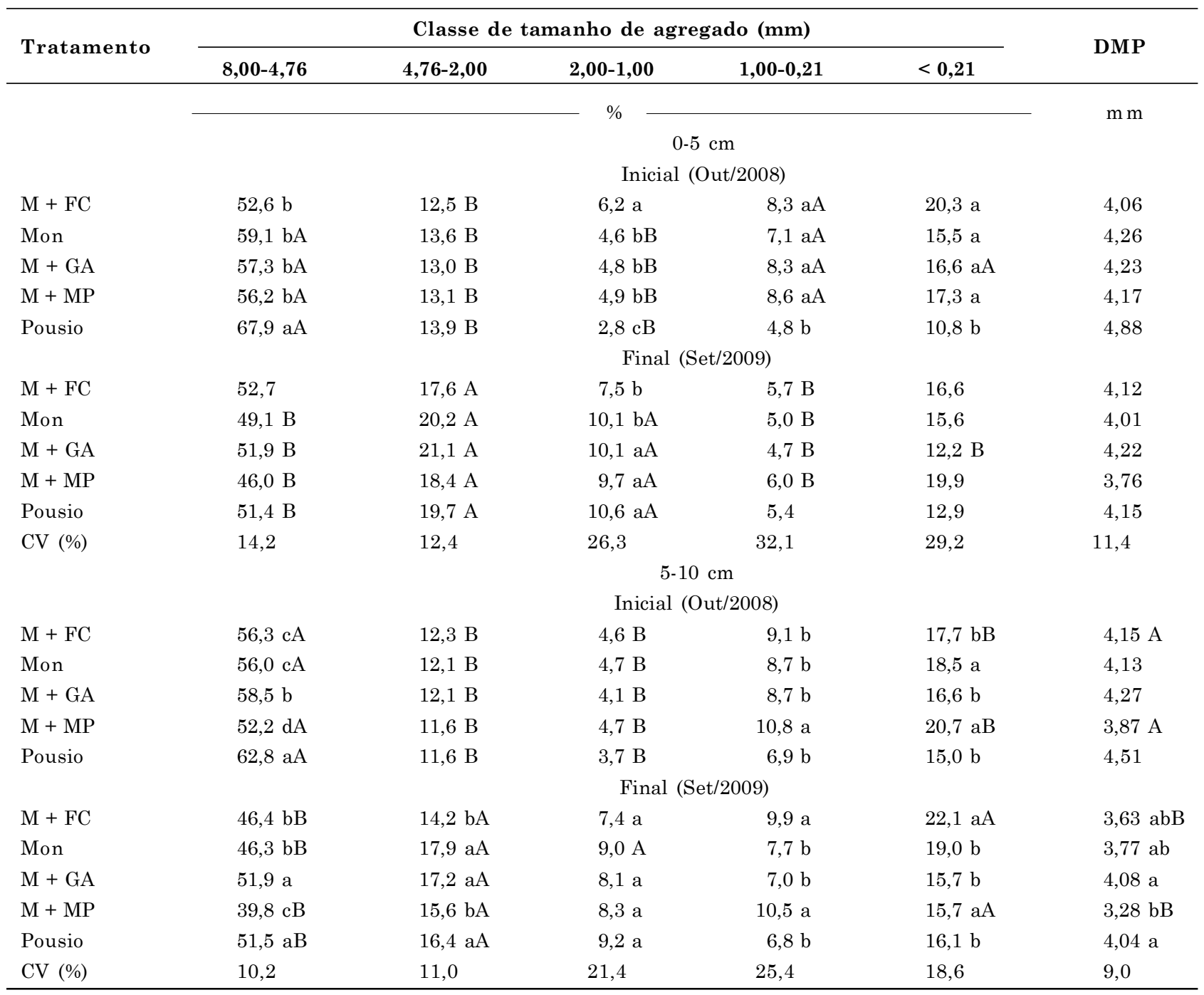

Letras minúsculas comparam médias, na coluna, entre os tratamentos dentro de cada fase de avaliação (inicial e final) na mesma profundidade amostrada. Letras maiúsculas comparam médias, na coluna, dos mesmos tratamentos entre as fases de avaliação (inicial vs final) para a mesma profundidade amostrada. Ausência de letras indica diferenças estatísticas não significativas. Comparações feitas pelo teste de Tukey a $5 \%$.

que esse consórcio passou, pois, durante o experimento, observaram-se intervalos de até 45 dias sem a ocorrência de precipitações maiores que $5 \mathrm{~mm}$, bem como temperaturas médias diárias acima de $22{ }^{\circ} \mathrm{C}$ (Figura 1). Nessas condições hídricas ocorre aprofundamento das raízes, o que faz com que diminua o raio de ação dessas condições. Embora o milho em monocultivo também passasse por igual estresse, nas entrelinhas dessa cultura havia diversas plantas espontâneas, com diversos sistemas radiculares ocupando melhor o espaço; dessa maneira, a presença dessas plantas pode ter contribuído para a relativa manutenção da estrutura do solo (Figura 2a,b; Quadro 3).

\section{CONCLUSÕES}

1. O consórcio de milho com guandu apresentou potencial de melhorias em atributos físicos do solo, influenciando positivamente para profundidade de 0$5 \mathrm{~cm}$, na densidade do solo, macroporosidade e porosidade total; e na profundidade de $5-10 \mathrm{~cm}$, para manutenção da estabilidade dos agregados entre as coletas.

2. Os consórcios de milho com feijão-caupi e milho com mucuna-preta apresentaram, na profundidade de $0-5 \mathrm{~cm}$, melhorias na densidade do solo, na macroporosidade e na porosidade total, 


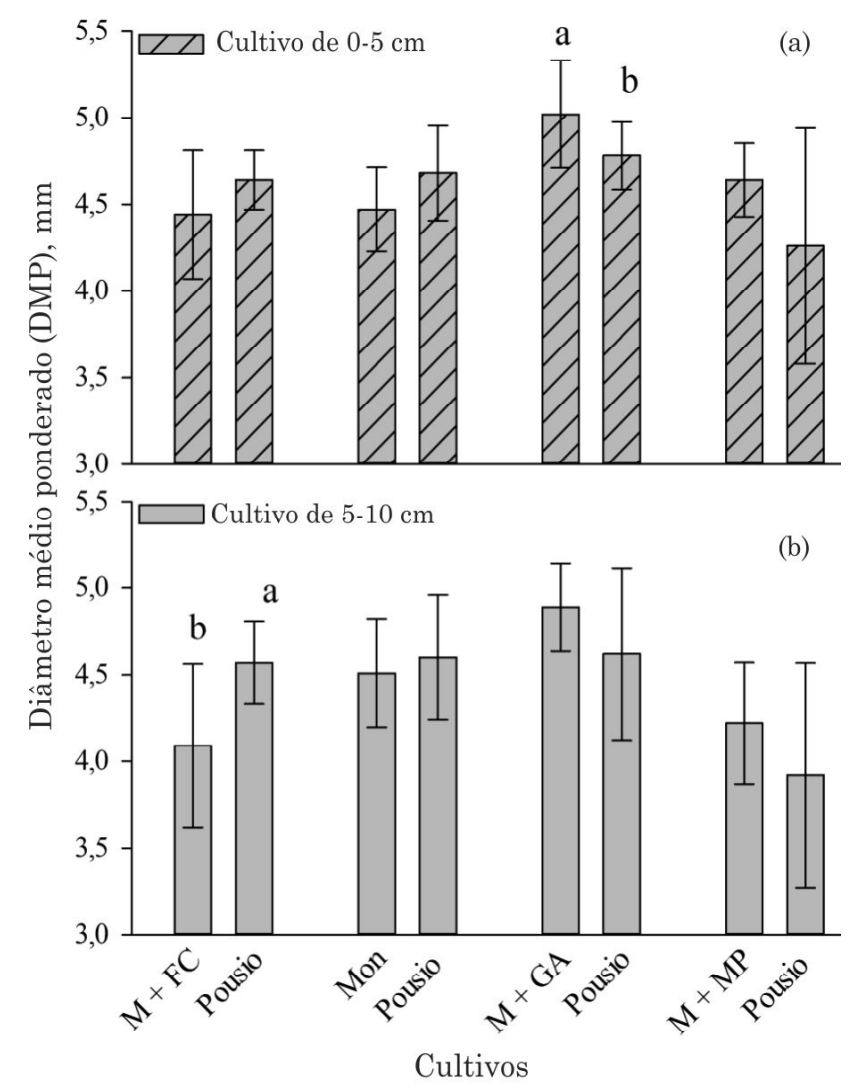

Figura 2. Diâmetro médio ponderado (DMP) para as profundidades de 0-5 (a) e $5-10 \mathrm{~cm}$ (b) do solo. Amostragem feita 30 dias após o manejo do consórcio (roçada e deposição da biomassa sobre o solo) para cada sistema de cultivo: milho + feijão-caupi (M + FC); milho em monocultivo (Mon); milho + guandu anão (M + GA) e milho + mucuna-preta (M + MP). Associada a cada coleta nos sistemas de cultivo, foi amostrada a área em pousio. Letras minúsculas diferentes nas barras indicam diferença entre o pousio e o cultivo correspondente, pelo teste de Tukey a $5 \%$.

porém ocasionaram redução do diâmetro médio ponderado na profundidade de $5-10 \mathrm{~cm}$, entre coletas.

\section{LITERATURA CITADA}

ABIVEN, S.; SAFYA MENASSERI, S. \& CHENU, C. The effects of organic inputs over time on soil aggregate stability - A literature analysis. Soil Biol. Biochem., 41:112, 2009.

ABREU, S.L.; REICHERT, J.M. \& REINERT, D.J. Escarificação mecânica e biológica para redução da compactação em Argissolo franco-arenoso sob plantio direto. R. Bras. Ci. Solo, 28:519-531, 2004.
AMBROSANO, E.J.; TRIVELIN, P.C.O.; CANTARELLA, H.; AMBROSANO, G.M.B.; SCHAMMASSV, E.A.; MURAOKAII, T.; GUIRADOI, N. \& ROSS, F. Nitrogen supply to corn from sunn hemp and velvet bean green manures. Sci. Agric., 66:386-394, 2009.

ANDRADE, R.S.; STONE, L.F. \& SILVEIRA, P.M. Culturas de cobertura e qualidade física de um Latossolo em plantio direto. R. Bras. Eng. Agríc. Amb., 13:411-418, 2009.

ARGENTON J.; ALBUQUERQUE, J.A.; BAYER, C. \& WILDNER, L.P. Comportamento de atributos relacionados com a forma da estrutura de Latossolo Vermelho sob sistemas de preparo e plantas de cobertura. R. Bras. Ci. Solo, 29:425-435, 2005.

BASTOS, R.S.; MENDONÇA, E.S.; ALVAREZ V., V.H.; CORREAA, M.M. \& COSTA, L.M. Formação e estabilização de agregados do solo influenciados por ciclos de umedecimento e secagem após adição de compostos orgânicos com diferentes características hidrofóbicas. R. Bras. Ci. Solo, 29:21-31, 2005.

CLAESSEN, M.E.C., org. Manual de métodos de análise de solo. 2.ed. Rio de Janeiro, Embrapa-CNPS, 1997. 212 p. il. (Documentos, 1)

COMISSÃO DE QUÍMICA E FERTILIDADE DO SOLO CQFS-RS/SC. Manual de adubação e calagem para os Estados do Rio Grande do Sul e Santa Catarina. 10.ed. Porto Alegre, Sociedade Brasileira de Ciência do Solo, 2004. 400p.

EDEN, M.; SCHJØNNING, P.; MOLDRUP, P. \& DE JONGE, L.W. Compaction and rotovation effects on soil pore characteristics of a loamy sand soil with contrasting organic matter content. Soil Use Manage., 27:340-349, 2011.

FERREIRA, D.F. Sisvar: A computer statistical analysis system. Ci. Agrotec., 35:1039-1042, 2011.

GENRO JUNIOR, S.A.; REINERT, D.J.; REICHERT, J.M. \& ALBUQUERQUE, J.A. Atributos físicos de um Latossolo Vermelho e produtividade de culturas cultivadas em sucessão e rotação. Ci. Rural, 39:65-73, 2009.

KEMPER, W.D. \& CHEPIL, W.S. Size distribution of aggregates. In: BLACK, C.A., ed. Methods of soil analysis: Physical and mineralogical properties, including statistics of measurement and sampling. Madison, American Society of Agronomy, 1965. Part 1. p.499-510.

LANZANOVA, M.E.; ELTZ, F.L.F.; NICOLOSO, R.S.; AMADO, T.J.C.; REINERT, D.J \& ROCHA, M.R. Atributos físicos de um Argissolo em sistemas de culturas de longa duração sob semeadura direta. R. Bras. Ci. Solo, 34:1333-1342, 2010 .

LOVATO, T.; MIELNICZUK, J.; BAYER, C. \& VEZZANI, F. Adição de carbono e nitrogênio e sua relação com estoques no solo e com o rendimento do milho em sistemas de manejo. R. Bras. Ci. Solo, 28:175-187, 2004.

MICHELON, C.J.; CARLESSO, R.; OLIVEIRA, Z.B.; KNIES, A.E.; PETRY, M.T. \& MARTINS, J.D. Funções de pedotransferência para estimativa da retenção de água em alguns solos do Rio Grande do Sul. Ci. Rural, 40:848853, 2010. 
PEREIRA, F.S.; ANDRIOLI, I.; BEUTLER, A.N.; ALMEIDA, C.X. \& PEREIRA, F.S. Physical quality of an Oxisol cultivated with maize submitted to cover crops in the precropping period. R. Bras. Ci. Solo, 34:211-218, 2010.

REICHERT, J.M.; LIMA, C.R.L.; DALMOLIN, R.S.D.; REINERT, D.J.; GONÇALVES, C. \& NUNES, M. Agregação de um Planossolo sistematizado há um ano e sob cultivo de arroz irrigado. Ci. Rural, 36:837-844, 2006.

REICHERT, J.M.; REINERT, D.J. \& BRAIDA, J.A. Qualidade dos solos e sustentabilidade de sistemas agrícolas. Ci. Amb., 27:29-48, 2003.

REINERT, D.J.; ALBUQUERQUE, J.A.; REICHERT, J.M.; AITA, C. \& ANDRADA, M.M.C. Limites críticos de densidade do solo para o crescimento de raízes de plantas de cobertura em Argissolo Vermelho. R. Bras. Ci. Solo, 32:1805-1816, 2008.

SILVA, A.P. \& KAY, B.D. Estimating the least limiting water range of soils from properties and management. Soil Sci. Soc. Am. J., 61:877-883, 1997.

SILVA, A.P.; IMHOFF, S. \& KAY, B.D. Plant response to mechanical resistance and air-filled porosity of soils under conventional and no tillage system. Sci. Agric., 61:451456, 2004.

SILVA, E.E.; DE-POLLI, H.; GUERRA, J.G.M.; MENEZES, E.L.A.; RESENDE, A.L.S.; OLIVEIRA, F.L. \& RIBEIRO, R.L.D. Sucessão entre cultivos orgânicos de milho e couve consorciados com leguminosas em plantio direto. Hortic. Bras., 29:57-62, 2011

SILVA, I.F. \& MIELNICZUK, J. Sistemas de cultivo e características do solo afetando a estabilidade de agregados. R. Bras. Ci. Solo, 22:311-317, 1998.
SILVA, M.A.S.; MAFRA, A.L.; ALBUQUERQUE, A.A.; DALLA ROSA, J.; BAYER, C. \& MIELNICZUK, J. Propriedades físicas e teor de carbono orgânico de um Argissolo Vermelho sob distintos sistemas de uso e manejo. R. Bras. Ci. Solo, 30:329-337, 2006.

SILVA, V.R.; REINERT, D.J. \& REICHERT, J.M. Densidade do solo, atributos químicos e sistema radicular do milho afetados pelo pastejo e manejo do solo. R. Bras. Ci. Solo, 24:191-199, 2000.

SIX, J.; BOSSUYT, H.; DEGRYZE, S. \& DENEF, K. A history of research on the link between (micro) agregates, soil biota, and soil organic matter dynamics. Soil Till. Res., 79:7-31, 2004.

STRECK, E.V.; KÄMPF, N.; DALMOLIN, R.S.D.; KLAMT, E.; NASCIMENTO, P.C.; SCHNEIDER, P.; GIASSON, E. \& PINTO, L.F.S. Solos do Rio Grande do Sul. 2.ed. Porto Alegre, Emater/RS-ASCAR, 2008. 222p.

TEDESCO, M.J.; GIANCELO, C.; BISSANI, C.A.; BOHNEN. \& VOLKWEISS, S.J. Análise de solo, plantas e outros materiais. 2.ed. Porto Alegre, Departamento de Solos, UFRGS. 1995. 174p. (Boletim Técnico, 5)

TISDALL, J.M. \& OADES, J.M. Organic matter and waterstable aggregates in soils. J. Soil Sci., 33:141-163, 1982.

VEZZANI, F.M. \& MIELNICZUK, J. Agregação e estoque de carbono em Argissolo submetido a diferentes práticas de manejo agrícola. R. Bras. Ci. Solo, 35:213-223, 2011.

WOHLENBERG, E.V.; REICHERT, J.M.; REINERT, D.J. \& BLUME, E. Dinâmica da agregação de um solo francoarenoso em cinco sistemas de culturas em rotação e em sucessão. R. Bras. Ci. Solo, 28:891-900, 2004. 